\title{
Design and Manufacture of a Solar-Powered Unmanned Aerial Vehicle for Civilian Surveillance Missions
}

\author{
Nelson Javier Pedraza Betancourth¹, Julio Enoc Parra Villamarin, John Jairo Vaca Rios, \\ Pedro David Bravo-Mosquera², Hernán Darío Cerón-Muñoz ${ }^{2}$
}

\begin{abstract}
In order to promote the development of renewable energy and take advantage of the new technologies for the benefit of sustainability, both the design and the manufacture methodologies of an experimental solarpowered unmanned aerial vehicle for civilian surveillance applications are presented. Throughout the document, it is provided the historical process around the development of the aircraft. Therefore, in the first part, it is shown the aerodynamic design, which includes the $2-D$ and $3-D$ analyses of the wing platform using numerical and experimental methods, the analytical design of the empennage configuration, and the main characteristics of the performance analysis. In addition, major systems and components that characterize the aircraft are described, such as the photovoltaic solar cells configuration as well as the electronics and control system into the unmanned aerial vehicle. Lastly, the modeling for the weights distribution of the components was carried out in a preliminary test using CAD tools. Thus, it was obtained a suitable process for the manufacture of the unmanned aerial vehicle, considering that the purpose of the aircraft is to be as light and aerodynamic as possible to accomplish the mission for which it was created.
\end{abstract}

KEYWORDS: Unmanned aerial vehicle, Aerodynamic design, Performance analysis, Photovoltaic solar cells, Manufacture processes.

\section{INTRODUCTION}

In the quest to find energy systems less harmful to the environment and more efficient than the currents, the processes of design and manufacture of a unmanned aerial vehicle (UAV) that operates with photovoltaic solar energy are described in this paper. The application of alternative energy sources in UAVs has established one of the broader challenges in its design and implementation, as specified by Ramanathan et al. (2007), promoting ideas through the use of solar cells (Lubkowski et al. 2010), liquid fuel cells (Fürrutter and Meyer 2009), lithiumpolymer (LiPo) batteries (Song and James 2000), among others. These energy sources can be a clean way to supply the power needs of the UAVs, such as the power plant system, the telemetry systems and the avionics. According to Herwitz et al. (2003) and MacCready et al. (1983), the application and use of new energy management systems are joined by the innovative and clean technology trends, which encourage the use of new energy resources in order to reduce the impact of the pollutants as the fossil fuels derived from the coal and petroleum.

Based on the experience of Austin (2010) and Wilkins et al. (2009), the determining factors for the use of alternative types of energy in UAVs are the mission and the size for which the vehicles are designed; these factors are reflected in the weight, which is one of the most important aspects when calculating the model. Therefore, it has been established, according to survey data, that hybrid energy configurations exist linking various types of energy; among the different alternatives are: the combination of hydrogen fuel cells $\left(\mathrm{LH}_{2}\right)$ with Diesel

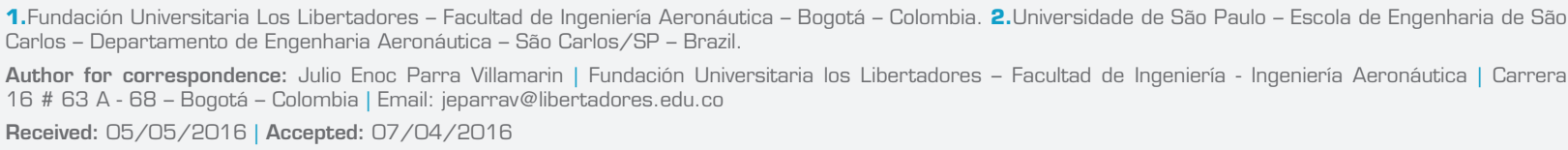


fuels or gas turbines (Nickol et al. 2007) and electric engines with solar cells (Brandt and Gilliam 1995; Romeo et al. 2007). Consequently, one can opt for the tendency to use renewable fuels. The efficient use of clean energy is attached to an important electronic development. Therefore, the adaptation of systemic mathematical algorithms from microcontrollers increases the energy efficiency and distributes the load capacity to all electronic components, establishing a system of energy management in the UAVs (Baoan et al. 2009).

According to data and models obtained by Nickol et al. (2007), Noth (2008) and Panagiotou et al. (2016), some analyzes and preliminary experiments have indicated that hybrid propulsion systems with solar energy offer excellent autonomy due to their energy storage capacity and continuous recharge. However, they require a large wing surface to the location of the solar panels. Nowadays, photovoltaic cells have been the largest source of alternative energy studied and applied. Therefore, there are references about 40 manned and unmanned experimental aircraft that take advantage of its features, performing missions in civil and military scenarios as: the Sky Sailor, the Helios and the Solar Impulse, that have successfully used photovoltaic solar energy as a source of power for their operation (Nickol et al. 2007; Sun et al. 2015).

The conceptual design of the UAV was carried out taking into account the optimal performance of the amount of harnessing solar energy achieved by the UAVs (Cestino 2006; Youngblood et al. 1984), which depends on the following environmental and technical factors: seasons of the year, due to the amount of sunlight that is exposed on the Earth's surface; time of the day, as a result of the sunlight intensity increase from sunrise until noon; the sun irradiance, exploitable in some periods of the day; efficiency of the photovoltaic cell, in which typical polycrystalline cell efficiencies are between 13 and 18\%; and the surface area of the solar cells, directly proportional to the amount of electric power supplied. Therefore, a larger wing surface was necessary to get better results from electrical power generation.

In this regard, a rigorous aerodynamic study was performed in order to select the best airfoil and the best wing configuration that meet the requirements of the aircraft. Thus, the wing was designed with a large aspect ratio (AR) of 17 , aiming to obtain the characteristics of a sailplane wing; at the wingtip, there is a taper ratio $(\lambda)$ of 0.375 for the sake of reduction of the wing tip stall effects. Thereby, the amount of 90 cells was distributed on the upper surface of the wing and the horizontal empennage, which are intended to power the motor and the subsystems of the aircraft. Due to the wingspan $(b)$ of $6 \mathrm{~m}$ and the maximum chord $(c)$ of
$0.4 \mathrm{~m}$, it was decided that the wings of the UAV load internally all the structural elements and the systems for the operation, simplifying the use of a fuselage and reducing the weight of the vehicle. Figure 1 shows the main dimensions of the wing platform of the UAV.

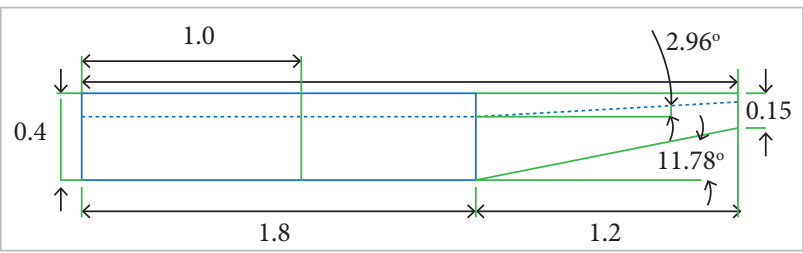

Figure 1.Wing dimensions in meters — UAV-SOLVENDUS full scale.

\section{UAV DESCRIPTION}

Currently, UAVs have become a very important device for the aviation and the industrial development, presenting ideal characteristics for recognition of inaccessible areas on missions than the traditional aircraft. In Colombia, UAVs designed and manufactured in different countries have been used in order to carry out different tasks in agriculture, aerial photography, security and other areas. However, in the last years, new academic research in UAVs have been proposed in the Colombian aeronautical sector, mainly in partnerships with Brazilian universities (Bravo-Mosquera et al. 2015; Herrera et al. 2014; Martínez and Cerón 2013; Parra et al. 2013).

Throughout this article, the methodological framework for the design of a surveillance UAV integrating the use of alternative energies and lightweight structures is presented. The UAV called SOLVENDUS (which means "worthy of being released") is a project that has been developed by the Fundación Universitaria Los Libertadores, Colombia, in cooperation with the Escola de Engenharia de São Carlos, Universidade de São Paulo, Brazil, in the period of $2010-2015$. The project was divided into 3 phases.

In the first one (2010), the establishment of the mission criteria was conducted. Therefore, a market study focused on the integration of alternative energy in aircrafts was developed. This gave way to consolidate the conceptual design processes of the UAV-SOLVENDUS.

At the second stage (2011 - 2012), the conceptual design of the UAV-SOLVENDUS was initiated, taking as reference the methodological proposals by Anderson Jr (1999), Raymer (1992) and Roskam (1997) in relation to different configurations for fixed wing aircraft. Thereby, the characterization of the UAV-SOLVENDUS mission in its different phases of flight as 
well as the selection of the different mechanical and electronic elements for the operation were established.

In the third phase (2013 - 2015), the complete development of the preliminary and detail design, including manufacture, was executed. In this regard, the aerodynamic design was performed using analytical, numerical and experimental methods in order to validate each stage calculated, aiming to analyze how would be the aerodynamic behavior of the UAV performing the established mission.

The solar cells configuration on the aircraft and the arrangement that best fits the needs of the electrical system were calculated. The upper surface of the airfoils should be treated as a polygonal line connected by several short line sections, as shown in Fig. 2. In this way, it is possible to arrange the photovoltaic cells without considerable deformations. This type of configuration can also be seen in Cestino (2006), Gao et al. (2014) and Romeo et al. (2007). On the other hand, new methodologies to optimize the construction of the aircraft were implemented following the global trend by applying manufacturing processes with composite materials. In this context, the material selection was based on the ASTM D3039. Nowadays, flight tests are being developed.

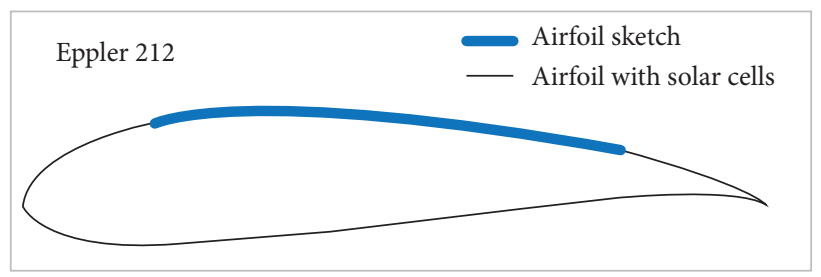

Figure 2. Configuration of solar panels on the selected wing airfoil.

\section{CONCEPTUAL DESIGN}

The conceptual design was based on an extensive parametric study on the characteristics of UAVs at the same category, aiming to interpret and analyze the main design features (geometric, aerodynamic and performance) that make up an aircraft with solar panels (Arai et al. 2014; Marta and Gamboa 2014). The particular requirements of the UAV-SOLVENDUS were established taking into account the first estimation of the maximum take-off weight (MTOW) and the desired power for flight. In this regard, most of the UAVs that operate with solar energy use battery systems as a supplement to its functionality. As a result, LiPo rechargeable batteries have adapted in flight, providing a continuous-cyclical storage, which supplies the necessary autonomy to carry out powerful flights, taking advantage of the daylight and storing energy for night missions.

The maximum efficiency offered by the solar panels is only able to electrically supply the electronic control and navigation systems. However, to supply the electrical engines, auxiliary batteries charged previously in the ground station were required. These reasons were the base to design a lightweight aircraft in order to reduce the energy consumption. According to Raymer (1992), the first estimation of the MTOW of an aircraft is supported by the following equation:

$$
\mathrm{MTOW}=W_{\text {fuel }}+W_{\text {crew }}+W_{\text {payload }}+W_{\text {empty }}
$$

where: $W$ means weight.

Analyzing the elements of the UAV-SOLVENDUS, the fuel weight is zero because the UAV does not operate with combustion engines; on the other hand, the crew and payload weights are irrelevant. Therefore, the MTOW of the UAV-SOLVENDUS is characterized by the components of the empty weight, which, by definition, are: Aircraft structure, Engines, Landing gear and Avionics. In this respect, the weight of the aircraft depended strictly on the manufacturing weight. Therefore, the use of materials with a high strength/weight ratio was necessary. This relation is the main characteristic of materials with high mechanical properties and low densities. Thus, composite materials were used to manufacture the experimental prototype of the UAV-SOLVENDUS, reducing the energy consumption of the power plant and increasing the performance of the aircraft.

From this perspective, the flight path and the mission profile studies for the UAV-SOLVENDUS were developed considering the following requirements and constraints:

- Low power required (aerodynamic efficiency and low structural weight).

- Low flight velocities.

- Use of solar energy through photovoltaic cells.

- Wing area sufficient for the distribution of cells.

- Mechanical, chemical or mixed fastening for the photovoltaic cells.

- Electric engines.

- Integration of autonomous navigation systems.

The mission profile of the UAV-SOLVENDUS is shown in Fig. 3. The UAV-SOLVENDUS moves at low flight regime, 
given the nature of its mission and the selection of its power plant system; this should maintain a high lift coefficient $\left(C_{L}\right)$ for the fulfillment of its operation. Therefore, airfoils that provide high lift coefficient at low speed flight were evaluated (Herrera et al. 2014).

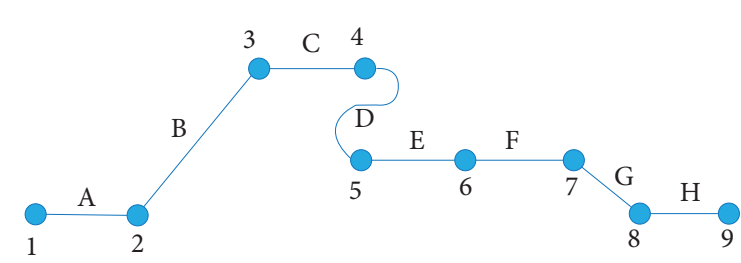

Transition points - 1: Engine ignition; 2: Take-off; 3: Operational altitude point; 4: Descent point for surveillance; 5: Start surveillance; 6: End surveillance; 7: Start descent; 8: Landing; 9: Stop engine. Flight stage - A: Take-off run; B: Climb; C: Cruise I; D: First descent; E: Surveillance; F: Cruise II; G: Runway approach; H: Landing.

Figure 3. Mission profile of the UAV-SOLVENDUS.

\section{PRELIMINARY DESIGN}

\section{AERODYNAMIC STUDY}

Initially, different airfoils were studied in order to determine the appropriate selection that meets the best features for the aircraft mission. Therefore, the best airfoil was chosen based on the "Stall" behavior and the drag polar curve. The airfoil selected was the Eppler 212, which presents a satisfactory aerodynamic performance at low Reynolds number. Its geometry allows attaching the solar panels. Twodimensional computational analysis using a free-software program was carried out, resolving the velocity field and the pressure distribution around the airfoil. These results are suitable for maneuverability use on the UAV-SOLVENDUS. Further information is reported in Herrera et al. (2014).

\section{THREE-DIMENSIONAL ANALYTIC DEVELOPMENT}

A free software called (Tornado ${ }^{\circledR} 2001$ ) was used for the preliminary analysis of the wing, which is a vortex lattice method. Figure 4 shows the lift distribution versus wingspan at an angle of attack equal to $4^{\circ}$ and geometric torsion in the wingtips. The twist angles analyzed were $0^{\circ},-2^{\circ}$ and $-4^{\circ}$, being negative when the leading edge was lowered relative to the trailing edge. Although distributions were similar, the twist angle equal to $-4^{\circ}$ was selected aiming to prevent the wing stalling on the wingtip region. The results show a lift force $(L)$ of $121.61 \mathrm{~N}$.

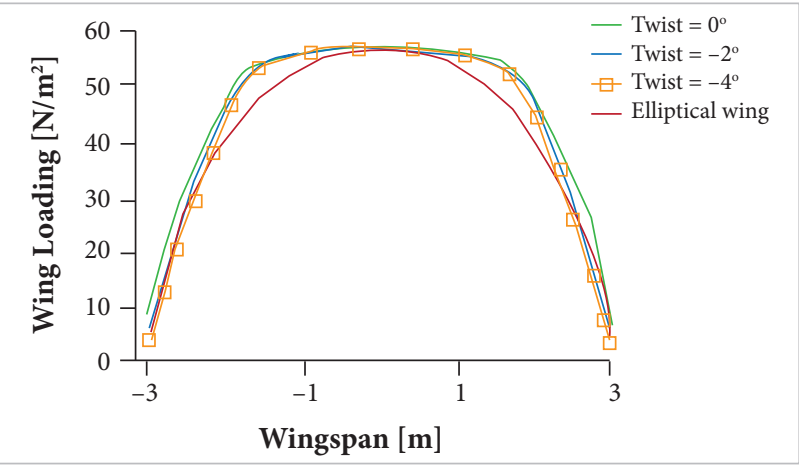

Figure 4. Comparison of lift distribution on the wing.

\section{COMPUTATIONAL ANALYSIS}

For this stage, the ANSYS $($-FLUENT code (ANSYS $® 2011$ ) was used in the modeling of airflow over the wing (scale 1:3). The computational domain used was large enough to avoid the fluid restriction in the simulations. It was discretized in both space and time through an appropriate mesh, where the Navier-Stokes equations were solved. In this regard, the distance to the nearest wall was set at $1 \times 10^{-4}$, resulting in a $\mathrm{Y}^{+} \approx 5$. The number of elements generated was $3.8 \times 10^{6}$, using an unstructured mesh (tetrahedral). The mesh generated for the wing model is shown in Fig. 5.

All the simulations were performed with the International Standard Atmosphere (ISA) parameters at the atmospheric conditions of São Carlos, São Paulo, Brazil, where the experiments were executed. The variation of the angle of attack was from $-4^{\circ}$ to $18^{\circ}$ at a Reynolds number of $2.05 \times 10^{5}$. The Shear Stress Transport (SST) turbulence model was chosen by its most common applications in the aerospace field related with limited flows by walls and simulations at low Reynolds numbers (ANSYS ${ }^{\circledR}$ 2011; Kontogiannis and Ekaterinaris 2013).

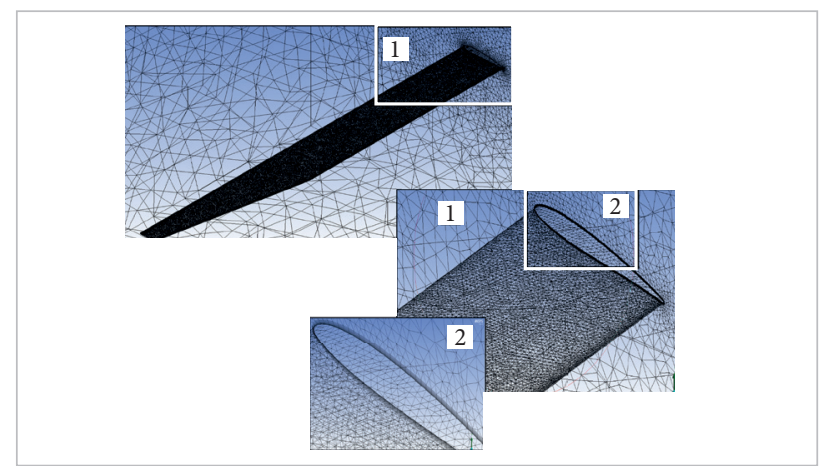

Figure 5. Unstructured mesh and grid details for the wing simulation. 
In addition to the good numerical approximations of the model's aerodynamic qualities compared with the experiments, the Computational Fluid Dynamics (CFD) simulations allowed to understand the behavior of the streamlines in each condition. In this connection, Figs. $6 \mathrm{a}$ and $6 \mathrm{~b}$ show the streamlines at angles of attack equal to $4^{\circ}$ and $10^{\circ}$, respectively. As can be observed, at $10^{\circ}$ there is a cross flow and fluid detachment compared with the simulations at $4^{\circ}$.

(a)

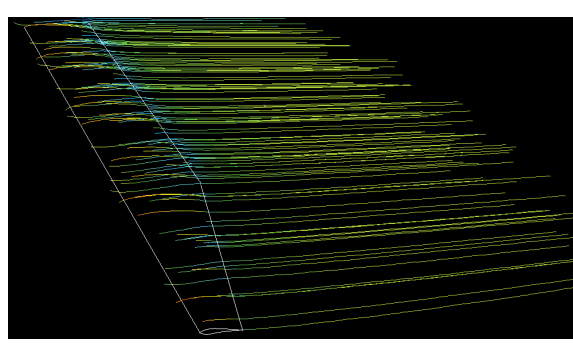

(b)

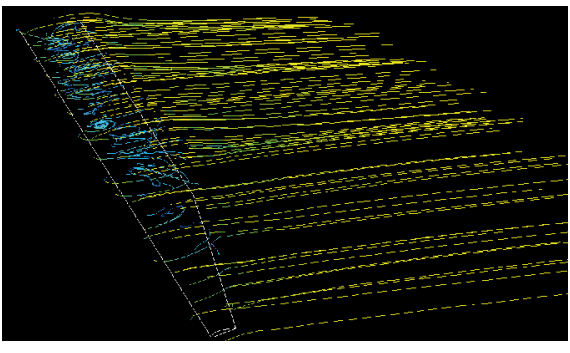

Figure 6. Streamlines at (a) $4^{\circ}$; (b) $10^{\circ}$.

\section{EXPERIMENTAL AERODYNAMIC MODEL}

Taking into account the dimensions of the test section of the wind tunnel (LAE, Fig. 7$)(1.3 \times 1.7 \times 3 \mathrm{~m})$ located at the Escola de Engenharia de São Carlos, Universidade de São Paulo (Catalano 2001), the wing model was built at a $1: 3$ scale. The experiments were executed at $25 \mathrm{~m} \cdot \mathrm{s}^{-1}$. For the manufacture of the model, the ribs were made in medium density fiberboard (MDF), with thickness of $6.3 \mathrm{~mm}$, the coating was made of polyvinyl chloride (PVC), with thickness of $0.5 \mathrm{~mm}$, and plastic tubes were built at $25 \%$ chord on the scale for the pressure taps. The experimental model used was a semi-span wing of $1 \mathrm{~m}, 0.05 \mathrm{~m}$ tip chord and $0.13 \mathrm{~m}$ in root

Figure 7. Wing model at the wing tunnel chord, as well as taper ratio of 0.375 , having a constant section of $0.60 \mathrm{~m}$ and a tip section of $0.40 \mathrm{~m}$.

\section{ACQUISITION AND ANALYSIS RESULTS}

Figure 8 presents the comparison of the numerical results obtained by the ANSYS ${ }^{\circledR}$-FLUENT code with the experimental data. In Fig. 8a, the numerical and experimental results at low angles of attack were very close, being obtained a numerical lift coefficient at zero angle of attack equal to 0.22 (for the experimental case, the angle was equal to 0.2). However, a divergence in the result begins to exist from $8^{\circ}$. From
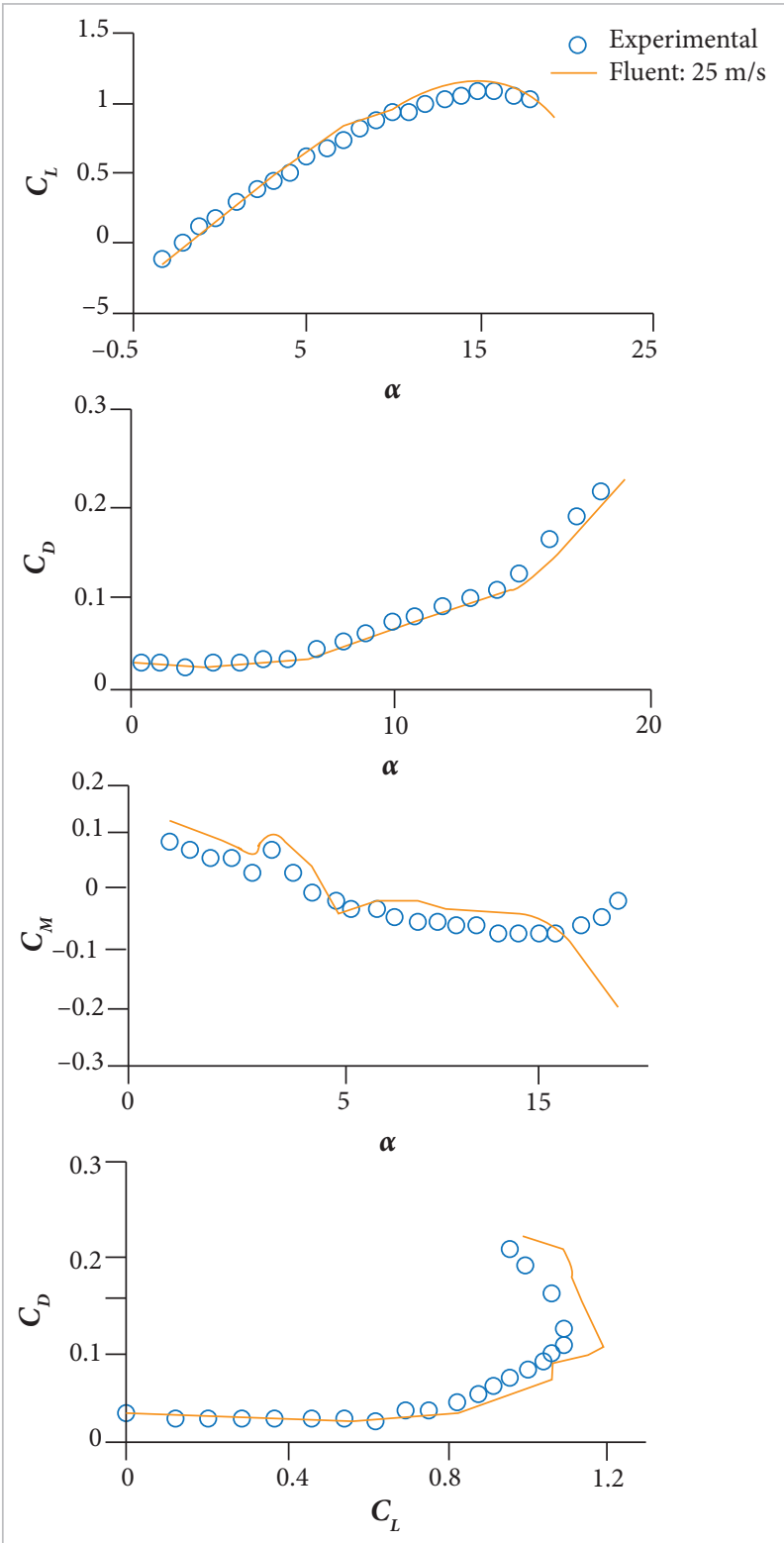

Figure 8. Aerodynamic curves - wing model. Scale 1:3. 
an angle of attack of $10^{\circ}$, the inclination of the curve changes and the growth rate of the lift coefficient decreases. As could be observed in Fig. 6b, the presence of cross flow suggests that the wing is beginning to stall. Furthermore, an excellent approxi mation of the experimental and numerical results regarding the drag coefficient $\left(C_{D}\right)$ was obtained, as can be seen in Fig. $8 \mathrm{~b}$, where the drag coefficient at zero angle of attack was practically set at 0.03. In Fig. 8c, both experimental and computational moment coefficients around the aerodynamic center were negative, confirming that the wing has a tendency to contribute to the stability of the aircraft. Figure $8 \mathrm{~d}$ shows the drag polar curve, in which it was observed that the maximum aerodynamic efficiency $(L / D)$ was set at $4^{\circ}$ for the experimental results and at $5^{\circ}$ for the numerical ones. Therefore, this angle of incidence was selected to optimize the mission profile, due to the reduction of the energy consumption.

Finally, in Table 1, the principal results of the total analysis of the wing platform are summarized. As a conclusion, the analytic, numerical and experimental results were well-developed, since the results are close, giving the knowledge of the aerodynamic behavior of the UAV-SOLVENDUS in the established mission.

Table 1. Comparison of aerodynamic coefficients.

\begin{tabular}{|c|c|c|c|}
\hline $\begin{array}{c}\text { Aerodynamic } \\
\text { parameters }\end{array}$ & Experimental & Numerical & Analytical \\
\hline Maximum $C_{L}$ & 1.11 & 1.18 & 1.35 \\
\hline$\alpha$ for $C_{L \max }$ & $15^{\circ}$ & $15^{\circ}$ & $10^{\circ}$ \\
\hline$C_{D}$ at zero $\alpha$ & 0.025 & 0.025 & 0.02 \\
\hline$\delta C_{M} / \delta \alpha$ & -0.0072 & -0.012 & -0.099 \\
\hline $\begin{array}{c}\text { Maximum } \\
(L / D)\end{array}$ & 22.23 & 24.88 & 34.34 \\
\hline $\begin{array}{c}\alpha \text { for }(L / D)_{\max } \\
\end{array}$ & $4^{\circ}$ & $5^{\circ}$ & $4^{\circ}$ \\
\hline
\end{tabular}

\section{EMPENNAGE DESIGN}

After meeting the aerodynamic and geometric characteristics of the wing platform, the empennage development was carried out in order to study the stability behavior of the UAV-SOLVENDUS. In this regard, 3 configurations were examined (conventional, v-tail, and twin-tail); the Twin-tail was selected and connected to the wing via booms. For the horizontal stabilizer, the initial surface area was calculated geometrically from the design conceptions. Therefore, the dimensions of the solar panels were considered, i.e. the chord of the horizontal stabilizer was limited by the size of the solar cells, regardless of the relative position that was assumed (long-wide). The dimensions of the solar cells are:
$14.6 \times 24.8 \mathrm{~cm}$. Thus, the horizontal stabilizer surface $\left(\mathrm{S}_{\mathrm{H}}\right)$ was $0.405 \mathrm{~m}^{2}$. The airfoil chosen was a NACA 0012 , determined by static-dynamic stability and control criteria. For the benefit of simplicity in manufacture, the vertical stabilizer uses a NACA 0009 , and its surface area is $0.23 \mathrm{~m}^{2}$.

According to the parameters shown in Fig. 9, a conceptual analysis of the longitudinal static stability was carried out, aiming to validate the configuration of the empennage design, where $A C_{w}$ is the aerodynamic center of the wing, $A C_{t}$ is the aerodynamic center of the tail and GC is the aircraft gravity center. The longitudinal stability contribution of the wing, the empennage, and the full configuration were calculated in order to maintain the moment coefficient derivative $(\partial C m / \partial \alpha<0)$ for the UAV. Figure 10 shows the moment coefficient at the center of gravity versus the angle of attack of each mentioned surfaces. As a result, the trim angle for the UAV-SOLVENDUS is set at $4^{\circ}$. The static margin (ST) for this case was at $17 \%$ of the mean aerodynamic chord (MAC), and the neutral point (NP) was at $47 \%$ of the MAC. The 3 views of the final prototype of the UAV-SOLVENDUS with its principal dimensions are shown in Fig. 11.

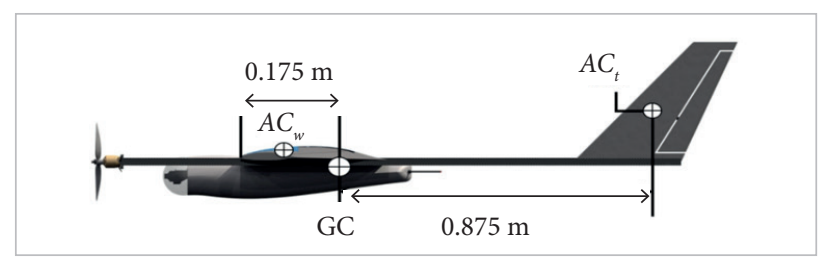

Figure 9. Static margin representation.

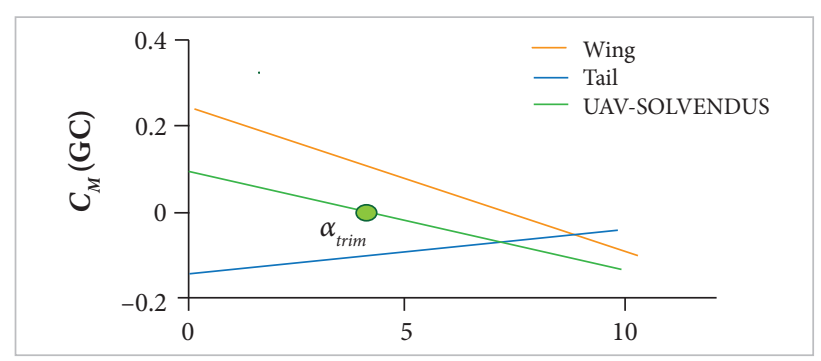

Figure 10. Stability contribution of the aerodynamic surfaces.

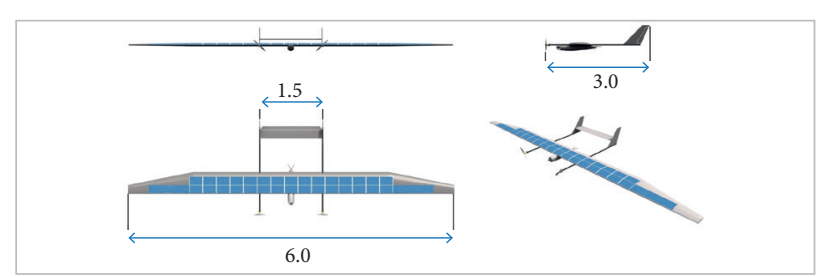

Figure 11. Dimensions of the final design of the UAV-SOLVENDUS in meters. 


\section{AIRCRAFT PERFORMANCE EVALUATION}

Initially, the thrust required for the UAV-SOLVENDUS was estimated regarding the cruise velocity equal to $25 \mathrm{~m} \cdot \mathrm{s}^{-1}$ and the MTOW of $12 \mathrm{~kg}$, determined in the conceptual design phase. Then:

$$
T=W /(L / D)
$$

For this case, the drag coefficient was analytically calculated, taking into account the form factor, the wet area, and the skin friction coefficient of the aerodynamic surfaces, in order to calculate the parasite drag and the characteristics of the wing configuration for the induced drag. As a result, the analytic drag polar equation for the UAV-SOLVENDUS was:

$$
C_{D}=0.032+0.0317 C_{L}^{2}
$$

In this regard, the first estimation of the thrust required for this condition was $T_{R}=6.75 \mathrm{~N}$. As a result, it was studied the thrust generated by different propellers for the engine Axi2820/12 (Axi Model Motors, 2015) in order to establish the differences or similarities in relation to the necessary force to move the aircraft in flight under the restrictions already mentioned. Thus, two propellers with $11 \times 8^{\prime \prime}$ were selected, providing a total thrust available $T=77.91 \mathrm{~N}$ and an efficiency $\eta_{p}=80.2 \%$. To obtain the capacity value of the electrical work generated by the engine Axi2820/12 (Axi Model Motors 2015) and the power required $\left(P_{R}\right)$ for the aircraft, the following relations were established:

$$
\begin{aligned}
& P=(I)^{2} \times R \\
& P_{R}=\sqrt{\left(2 W^{3} C_{D}^{2}\right) /\left(\rho S C_{L}^{3}\right)}
\end{aligned}
$$

where: $P$ is the electrical power; $\rho$ is the density; $S$ is the wing surface; the values for electric current $(I)$ vary between 15 to $25 \mathrm{~A}$; the motor resistance $(R)$ is set at $0.059 \Omega$.

The engine manufacturer (Axi Model Motors 2015) assumed these values as ideal. Therefore, these were selected as the initial parameters for calculating the engine performance. In Fig. 12, the thrust and power required by the UAV-SOLVENDUS are shown at different velocities. As can be observed, for the $(L / D)_{\text {max }}$, the thrust and power required presented the lower values available, and, for the cruise velocity, the thrust and power required for the UAV-SOLVENDUS were $15 \mathrm{~N}$ and $400 \mathrm{~W}$, respectively.

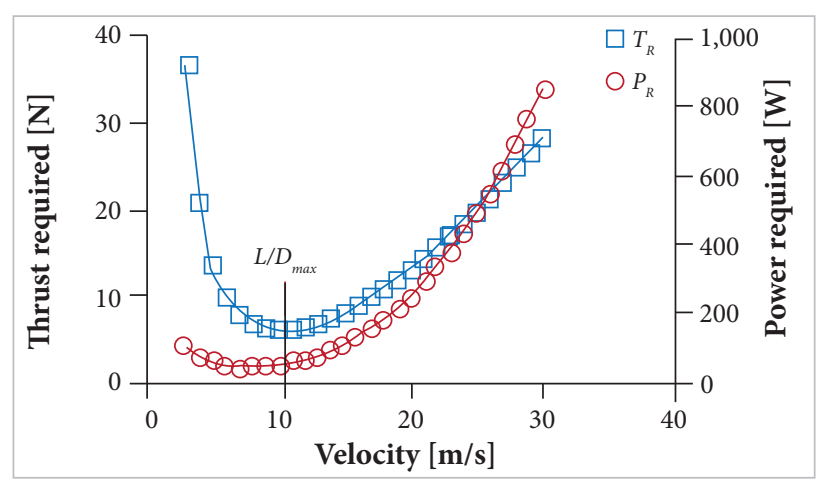

Figure 12. Thrust and power required by the UAV-SOLVENDUS.

\section{PHOTOVOLTAIC SOLAR CELLS CONFIGURATION}

The photovoltaic solar system has the purpose of supplying electrical energy to the internal systems of the aircraft. The motors are the components that present higher energy consumption. A motor Axi2820/12 was selected, which has a maximum capacity of $500 \mathrm{~W}$ and works with LiPo batteries of 3 and 4 cells. In this way, each motor operates with voltages ranging between 11.1 and $14.8 \mathrm{~V}$, and the current varies between 45 and $30 \mathrm{~A}$. The other elements that consume power are the avionics and servos, which operate at 5 and $6 \mathrm{~V}$ with currents of $4.5 \mathrm{~A}$.

In order to determine the best arrangement according to the needs of the avionics and servos systems, it was necessary to carry out a characterization of each solar cell under real operating conditions. Figure 13 shows the behavior of solar radiation against time during the course of the tests. This reflected the drop in the level of solar radiation with dusk, confirming that the best time of the day for test flights is between 13:00 and 15:00 pm (Arai et al. 2014; Chang et al. 2014). Table 2 shows the environmental test conditions. In order to consider the variation of the solar radiation along the day, voltage and current were measured at different times of the day. In this

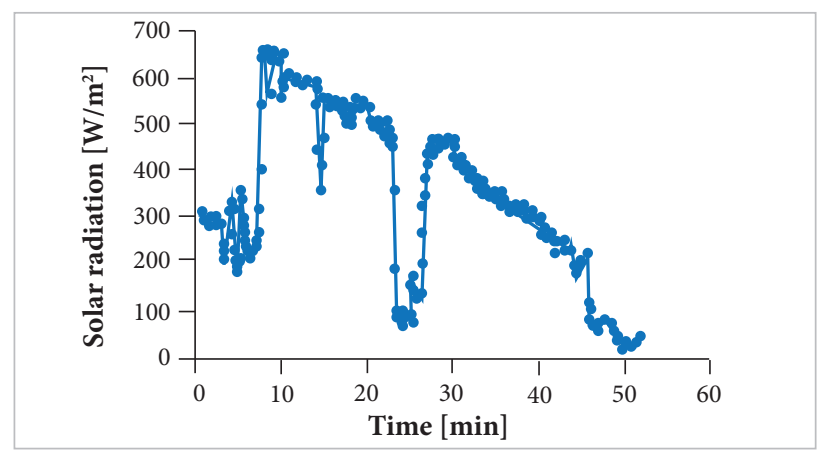

Figure 13. Radiation levels versus time. 
manner, the voltage of the cells (V-cell) changed from 9 to $10 \mathrm{~V}$ (Fig. 14a), and the current (I-cell) changed with a rate of $0.1273 \mathrm{~mA} /\left(\mathrm{W} \cdot \mathrm{m}^{-2}\right)$ (Fig. 14b).

Regarding avionics and servos requirements, a hybrid configuration was implemented, which has pairs of cells connected in series, in order to produce higher voltages (Fig. 15a), and all the pairs connected in parallel with the

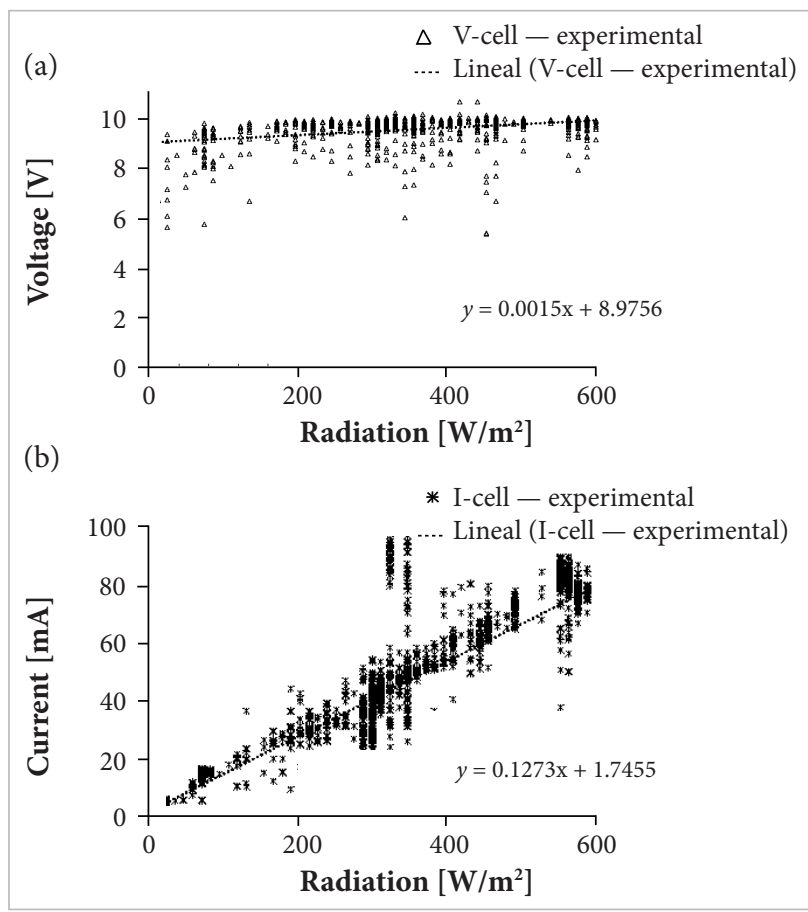

Figure 14. Cells voltages (a) e current (b) under operating conditions (temperature between 19 and $20^{\circ} \mathrm{C}$ ).

Table 2. Environmental test conditions of the photovoltaic solar panels.

\begin{tabular}{|c|c|c|c|}
\hline Test & $\begin{array}{c}\text { Environmental } \\
\text { temperature } \\
{\left[{ }^{\circ} \text { C] }\right.}\end{array}$ & $\begin{array}{r}\text { Time of the } \\
\text { day } \\
{[24 \text { h] }}\end{array}$ & Weather \\
\hline 1 & $19-20$ & $14: 05$ & Sunny \\
\hline 2 & $19-20$ & $14: 10$ & Sunny \\
\hline 3 & $19-20$ & $14: 15$ & Sunny \\
\hline 4 & $19-20$ & $14: 20$ & Sunny \\
\hline 5 & $19-20$ & $14: 25$ & Sunny \\
\hline 6 & $19-20$ & $14: 30$ & Sunny \\
\hline 7 & $19-20$ & $14: 35$ & Sunny \\
\hline 8 & $18-19$ & $14: 40$ pm & Partly cloudy \\
\hline 9 & $18-19$ & $14: 45$ pm & Partly cloudy \\
\hline 10 & $18-19$ & $14: 50$ pm & Partly cloudy \\
\hline & & & \\
\hline
\end{tabular}

aim of increasing the current of the circuit (Fig. 15b). The cells were placed over the entire surface of the wing and the horizontal stabilizer, consisting of 45 pairs of cells that provide 4,500 mA with voltage ranging between 14 and $20 \mathrm{~V}$. Figure 16 shows the scheme of the final configuration of the solar panel system.

On the other hand, in order to determine the efficiency of the cells, it was necessary to know their voltage-current curve characteristics. This curve is provided by the manufacturer PowerFilm RC7.2-75 PSA (PowerFilm Solar® 2006) and is shown in Fig. 17. The points $A$ and $B$ represent certain conditions given by the load, resistance and voltage. Bearing in mind that the temperature of the cells do not match the ambient temperature, it was necessary to estimate the variation of their temperature in relation to the environmental temperature. According to Mattos et al. (2013) and Skoplaki and Palyvos (2009), the efficiency of the cells at ambient temperature, between 19 and $20^{\circ} \mathrm{C}$, oscillates in a range from 4 to $7 \%$. As there is variability in the electrical properties of

(a)

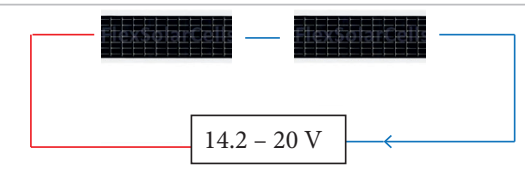

(b)

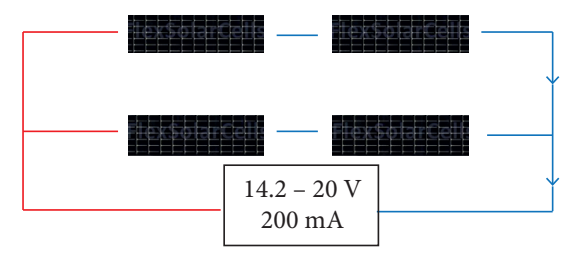

Figure 15. Cells connected (a) series; (b) hybrid array.

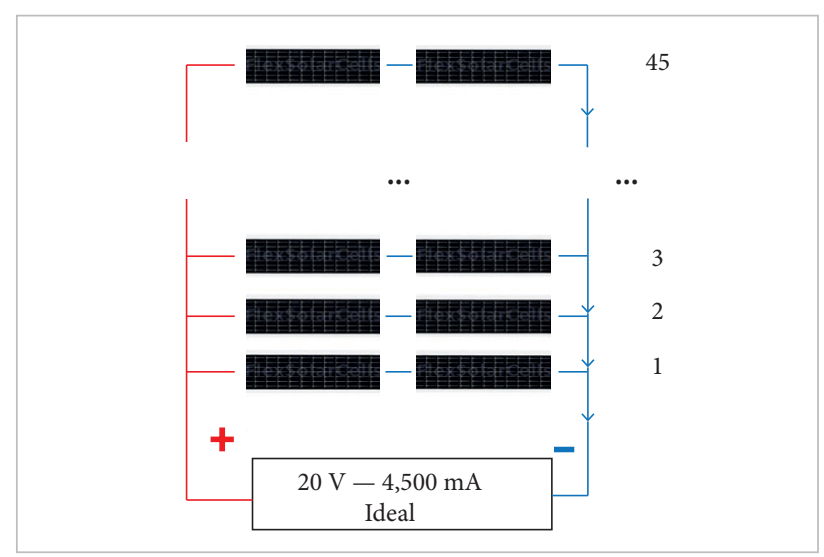

Figure 16. Scheme of the final configuration of the solar panels. 
each cell, the selection of the cells arrangement was carried out taking into account that the cells connected in pairs have to provide similar efficiencies in the hybrid configuration. The pairs of cells for the hybrid configuration were made with those of similar efficiencies.

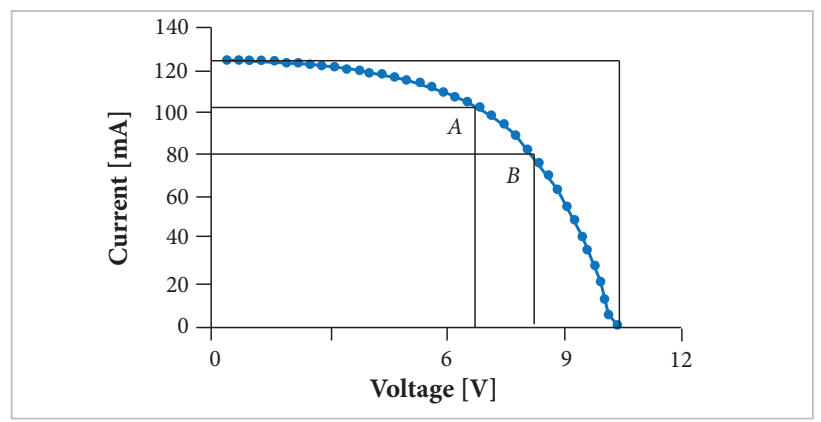

Figure 17. $100 \%$ Sun — standard test conditions, AM 1.5. Cell efficiency.

\section{ELECTRONICS AND CONTROL SYSTEMS}

The internal structure of the UAV requires electronic devices that allow identifying and establishing the attitude and position. For the attitude of the UAV-SOLVENDUS, environmental data are collected through a set of devices (Type COST, Commercial off-the-shelf), as inertial measurement unit (IMU), which perform the angular speeds $(P, Q$, and $R$ ) measurements in the movements of pitch, roll and yaw - with its respective Moment $\left(M_{a}\right)$ in addition to the measurement of acceleration in the $x, y$, and $z$ axes using accelerometers and gyroscopes $\left(A_{c}\right)$ integrated with a micro-controller. The variables that are acquired from these sensors are subjected to an estimation process called Kalman filter, whereby it is possible to determine the attitude of the UAV.

In order to position the UAV and enable the navigation, a global position system (GPS) device was used. The altitude on the take-off and landing stages was determined by a sonar and an altimeter. High altitudes (above 2,000 m) were measured with a barometric altimeter. An additional sensor is the magnetometer or digital compass, which revealed the azimuth of the UAV. The scheme of these devices can be observed in Fig. 18. Considering that the power offered by the solar panels are only able to supply electrically the electronic control and aircraft navigation systems, the supply of the propulsion system must be performed by a set of auxiliary batteries ( $2 \mathrm{~S}-3 \mathrm{~S}$ LiPo batteries), preloaded on the ground station. The electricity produced by the solar panels goes directly to the batteries that store and distribute energy to all the electronic components connected to this system. Batteries and panels are connected to a 12-V 2.2-A step-down voltage regulator D24V22F12 in order to keep a constant voltage of $12 \mathrm{~V}$. The energy distribution of the electrical system is shown in Fig. 19.

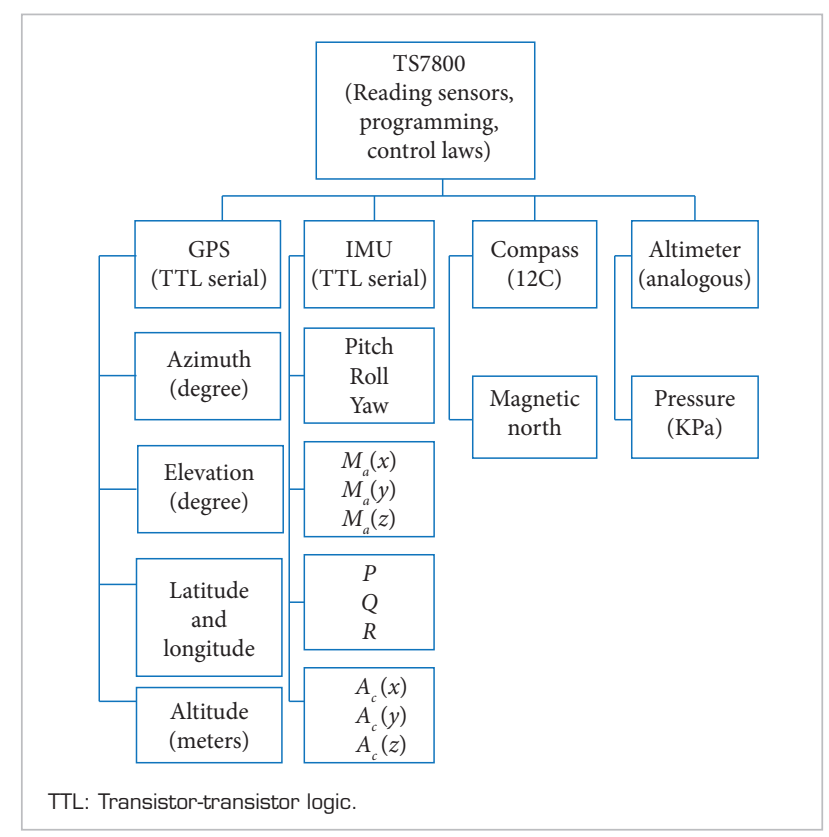

Figure 18. Scheme of the navigation system.

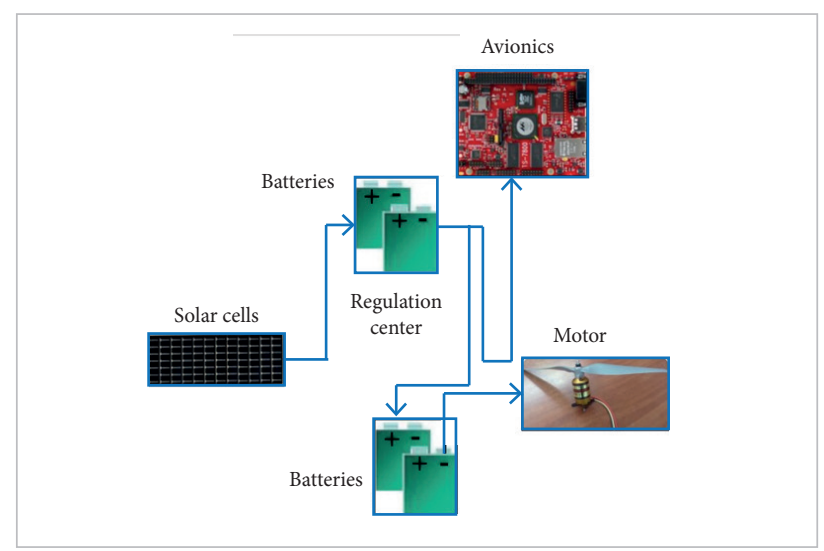

Figure 19. Energy distribution.

\section{MANUFACTURE PROCESS}

For structural design of the aircraft, it is important to consider the materials used for manufacturing. In this regard, for this project, the properties of the composite materials were studied, and it was decided to use carbon fiber. Depending on the component and its complexity, the methodology of 
using the materials and the assembly procedures can change; since a large part of the components were made of composite materials, manufacturing methods were defined, e.g. manual contact molding or vacuum packing.

Methodologies of vacuum packing were selected, whose advantages were:

- Allow the realization of parts in small and medium series, without restriction of shapes and sizes.

- Uniform distribution of the resin and reduction of the air inclusions, resulting in good mechanical properties.

- Good surface appearance of both sides.

A suitable process for the manufacture of the parts was carried out; it should be noted that the inputs must be placed in a correct and precise order, aiming to obtain a suitable finishing. Figure 20 shows the correct order of the inputs placed. Before to start the construction, the detail design of each part of the main surfaces was performed using CAD tools. With these designs, it was possible to adjust the distribution of the structural parts mainly in the wings and the empennage. Figure 21 shows the distribution of the ribs and stringers in the wing and the empennage. Jigs were used in order to control the location of the components during this process. Besides serving for correct alignment, jigs fulfil the function of temporary supports during assembly model.

After mounting the jigs, the ribs (which were formed by a core of light wood, $1.5 \mathrm{~mm}$ thick, and 2 layers of carbon fiber, $0.7 \mathrm{~mm}$ thick, forming a "sandwich", Fig. 22, with a thickness of $2.2 \mathrm{~mm}$ ) were located on the jigs and joined to the beam. At the

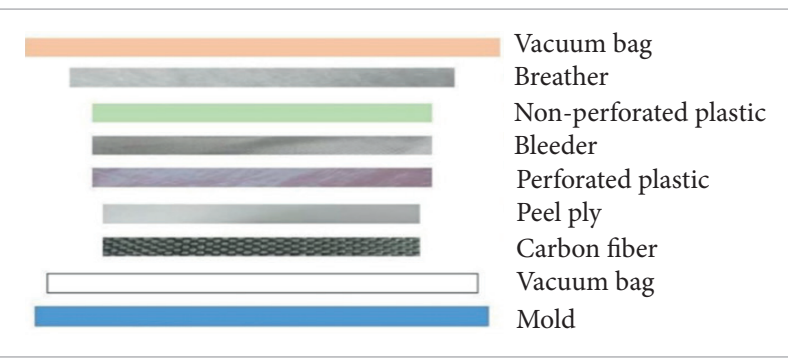

Figure 20. Materials and supplies ordered and used in vacuum.

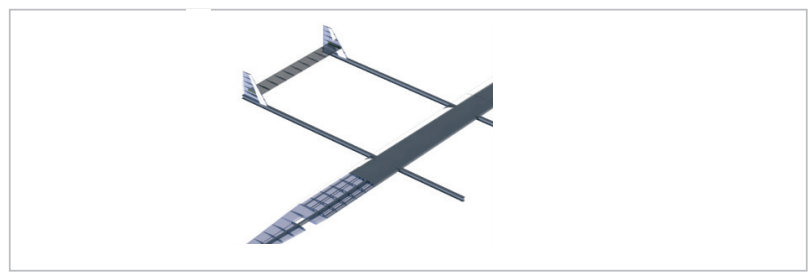

Figure 21. Distribution of ribs and stringers on the wing and empennage. end of the process, 3 sections of $2 \mathrm{~m}$ each were built for the wing. The 3 wing sections were joined with screws for an easy assembly and disassembly. The fuselage manufacturing was made in sections. In the first instance, the fuselage CAD model was printed in a 3-D printer machine; this impression served to make the molds for manufacturing in composite material. Figure 23 shows the molds and the final manufacture of the fuselage. On the other hand, the UAV skin manufacture was performed in 6 sections, distributing inputs in the correct order as pointed in Fig. 20. As a result, each layer presented $2.20 \times 0.40 \mathrm{~m}$ and weight of $173.4 \mathrm{~g}$. Figure 24 shows the aircraft skin manufacture processes.

Each rib of the aircraft was check to ensure adherence of the skin with the wing structure and the empennage. During this process, the ribs and the main beam of the UAV were reinforced. The adhesion of the skin with the ribs of the wings was carried out with resin by the stringers designed; the union covered the leading edge and part of the main beam. Figure 25 shows the joint between the skin and ribs. Finally, tail booms were built with an "I" profile with carbon fiber and light wood cored, which were joined to the vertical stabilizers with 6 screws on each side. Figure 26 shows the final assembly of the UAVSOLVENDUS ready to flight.

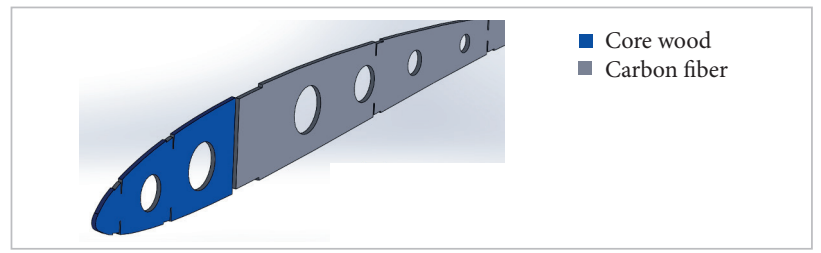

Figure 22. Wing rib detail.

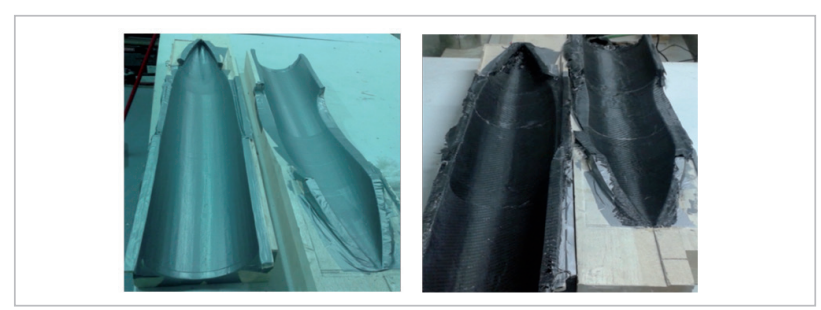

Figure 23. Fuselage manufacture.
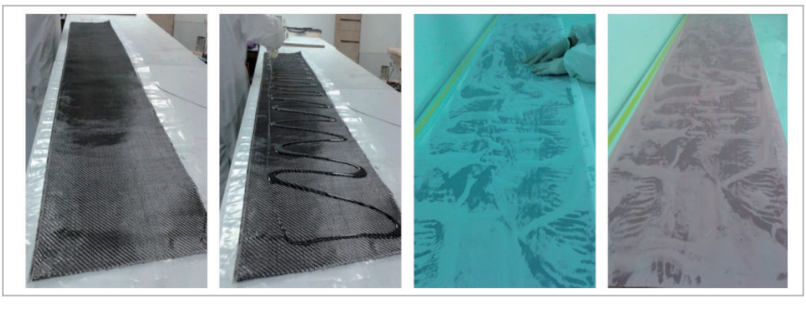

Figure 24. Skin manufacture. 


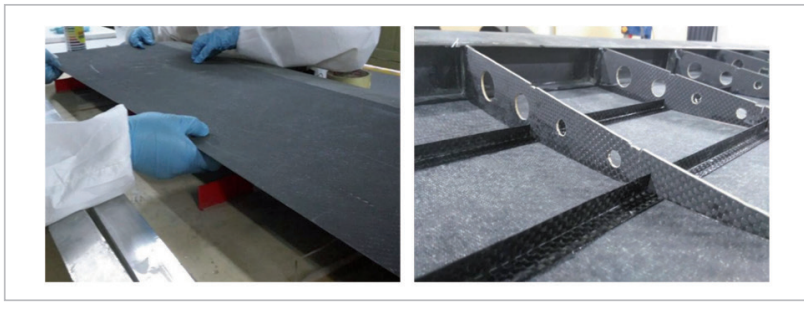

Figure 25. Joint between skin and ribs.

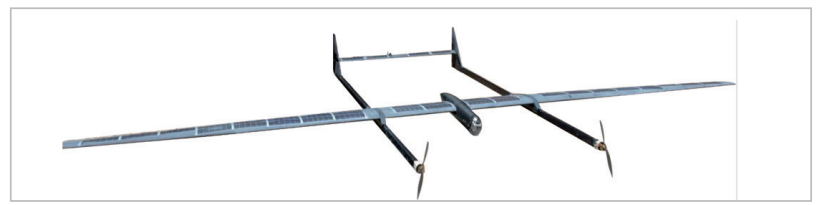

Figure 26. UAV-SOLVENDUS experimental prototype.

\section{CONCLUSIONS}

The first prototype of a light, solar-powered UAV for civilian surveillance missions was designed and successfully constructed, being one of the first projects that are registered in Colombia as viable due to the integration of independent complex systems. It has expanded the discussion of the development of unmanned systems designs with the aim of performing missions that could not be made with traditional aircraft. The results obtained with analytical, computational, and experimental methods have served to enrich the research exercise around the design of the UAV-SOLVENDUS. Therefore, it was possible to analyze and validate the main findings during the design process, which are summarized as follows:

- CFD tools were used in order to study and compare the experiments performed on the wing model. The aerodynamic efficiency $(L / D)$ obtained in the wing design method reveals that it is maximum at $4^{\circ}$. Therefore, this angle of attack is recommended for better aerodynamic efficiency at cruise flight for the UAV.

- The combination of improvements proposed by the authors, as the increase in the wingspan and the wing surface, lead to a greater range and endurance of the aircraft. Therefore, the UAV-SOLVENDUS is a more economical and eco-friendly aircraft, compared with the other UAVs destined to perform similar missions.

- For this first prototype, an experimental study for the solar panel system characterization was executed, with the aim of analyzing the voltage, current, and power of UAV requirements according to different levels of radiation in real operating conditions. As a result, the most appropriate cells arrangement (hybrid) was chosen, in order to supply the power requirements for the avionics equipment, since the propulsion system must be energized with auxiliary batteries.

- The performance of the current solar power system is under evaluation. Until now, its behavior has been acceptable to supply the power necessary to the onboarding system, even though it has not been wholly satisfactory to supply energy to the propulsion system, and electrical batteries are still necessary.

- The manufacture process was developed based on ASTM D3039. The features offered by the carbon fiber were appropriate for the model; factors such as weight, strength, and behavior in environmental conditions were remarkably outstanding in the performed test.

Finally, through this investigation, it was possible to demonstrate the benefits of using renewable energies in the aeronautical engineering field, allowing to know new alternatives to the use of photovoltaic solar panels on aircraft models that seek to optimize the fuel consumption, keeping high values of endurance and range.

\section{ACKNOWLEDGEMENTS}

The authors express their gratitude to the Fundación Universitaria Los Libertadores, for the financial support, as well as to its Oficina de Relaciones Interinstitucionales (ORI), for the support to the Student Exchange Program. The Grupo de Investigación en Ciencias Aeroespaciales (GICA), for the cooperation and devotion on the development of this project. Prof.Fernando Martini Catalano, for the support in the preparation of the experiments at the Laboratório de Aerodinâmica, Dep. Engenharia Aeronáutica, Escola de Engenharia de São Carlos, Universidade de São Paulo.

\section{AUTHOR'S CONTRIBUTION}

Betancourth NJP, Villamarin JEP and Rios JJV conceived the idea and co-wrote the text. Cerón-Muñoz HD headed the current project and co-wrote the text. Bravo-Mosquera PD, aided on the calculations, prepared the figures and co-wrote the main text. All authors discussed the results and commented on the manuscript. 


\section{REFERENCES}

Anderson Jr JD (1999) Aircraft performance and design. Boston: WCB/ McGraw-Hill.

ANSYS® (2011) ANSYS FLUENT theory guide. Canonsburg: ANSYS, Inc.

Arai N, Harasani W, Hiraoka K (2014) Conceptual design of solar UAV for long endurance. St. Petersburg: International Council of Aeronautical Science.

Austin R (2010) Unmanned aircraft systems: UAVS design, development and deployment. Chichester: Wiley.

Axi Model Motors (2015) Axi2820/12 gold line, data sheet, technical specification, catalogue products; [accessed 2016 Feb 24]. https:// uww.modelmotors.cz/

Baoan L, Zhihua L, Xinjun L (2009) Research of UAV engine fault prediction based on particle filter. Proceedings of the 9th International Conference on Electronic Measurement and Instruments; Beijing, China.

Brandt SA, Gilliam FT (1995) Design analysis methodology for solarpowered aircraft. J Aircraft 32(4):703-709. doi: 10.2514/3.46780

Bravo-Mosquera P, Uribe A, Catalano F, Abdalla A (2015) Parametric conceptual design of a UAV for superficial volcano monitoring. Proceedings of the 23rd ABCM International Congress of Mechanical Engineering; Rio de Janeiro, Brazil.

Catalano $F$ (2001) The new closed circuit wind tunnel of the aircraft laboratory of University of São Paulo. Proceedings of the 16th Brazilian Congress of Mechanical Engineering; Uberlândia, Brazil.

Cestino E (2006) Design of solar high altitude long endurance aircraft for multi payload and operations. Aero Sci Tech 10(6):541-550. doi: 10.1016/j.ast.2006.06.001

Chang M, Zhou Z, Wang R, Xu X (2014) A general design methodology for year-sound solar-powered stratospheric UAVs from low to middle latitudes. St. Petersburg: International Council of Aeronautical Science.

Fürrutter MK, Meyer J (2009) Small fuel cell powering an unmanned aerial vehicle. Proceedings of the AFRICON 2009; Naibori, Kenia.

Gao X, Hou Z, Guo Z, Chen X (2014) Design and performance test of a twin fuselage configuration solar-powered UAV. St. Petersburg: International Council of Aeronautical Science.

Herrera J, Silva N, Tellez C, Cerón H, Pedraza N (2014) Análisis aerodinámico computacional y experimental para el ala de un mini vehículo aéreo no tripulado (VANT). Proceedings of the 8th Congresso Nacional de Engenharia Mecânica; Uberlândia, Brazil.

Herwitz S, Dunagan S, Sullivan D, Higgins R, Johnson L, Zheng J, Aoyagi M (2003) Solar-powered UAV mission for agricultural decision support. Proceedings of the International Geoscience and Remote Sensing Symposium; Moffett Field, USA.

Kontogiannis G, Ekaterinaris J (2013) Design, performance evaluation and optimization of a UAV. Aero Sci Tech 29(1):339-350. doi: 10.1016/j. ast.2013.04.005

Lubkowski S, Jones B, Rojas E, Morris D (2010) Trade-off analysis of regenerative power source for long duration loitering Airship. Proceedings of the Systems and Information Engineering Design Symposium (SIEDSIEEE); Charlottesville, USA.

MacCready PB, Lissaman PBS, Morgan WR, Burke JD(1983)Sun-powered aircraft designs. J Aircraft 20(6):487-493. doi: 10.2514/3.44898
Marta A, Gamboa P (2014) Long endurance electric UAV for civilian surveillance missions. St. Petersburg: International Council of Aeronautical Science.

Martínez P, Cerón H (2013) Análise computacional das características aerodinâmicas de um VANT em configuração box-wing. Proceedings of the 6th Congreso Internacional de Ingeniería Mecánica (CIMM); Barranquilla, Colombia.

Mattos BS, Secco NR, Salles EF (2013) Optimal design of a high-altitude solar-powered unmanned airplane. J Aerosp Technol Manag 5(3):349361. doi: 10.5028/jatm.v5i3.223

Nickol L, Guynn M, Kohout L, Ozoroski T (2007) High altitude long endurance air vehicle analysis of alternatives and technology requirements development. Proceedings of the 45th Aerospace Sciences Meeting and Exhibit; Reno, USA.

Noth A (2008) Design of solar powered airplanes for continuous flight ( $\mathrm{PhD}$ thesis). Zürich: ETH Zürich.

Panagiotou P, Tsavlidis I, Yakinthos K (2016) Conceptual design of a hybrid solar MALE UAV. Aero Sci Tech 53:207-219. doi: 10.1016 ast.2016.03.023

Parra J, Cerón H, Gómez A (2013) Pruebas aerodinámicas experimentales de aeronave con alta relación de aspecto a bajos Reynolds. Proceedings of the 6th Congreso Internacional de Ingeniería Mecánica (CIMM); Barranquilla, Colombia.

PowerFilm Solar® (2OO6) RC7.2-75 PSAF. Datasheet. Catalogue products; [accessed 2016 May 1]. http://www.powerfilmsolar.com/

Ramanathan V, Ramana MV, Roberts G, Kim D, Corrigan C, Chung C, Winker $\mathrm{D}$ (2007) Warming trends in Asia amplified by brown cloud solar absorption. Nature 448:575-578. doi: 10.1038/nature06019

Raymer DP (1992) Aircraft design: a conceptual approach. Washington: American Institute of Aeronautics and Astronautics.

Romeo G, Frulla G, Cestino E (2007) Design of a high-altitude long-endurance solar-powered unmanned air vehicle for multi-payload and operations. Proc IMEG J Aero Eng 221(2):199-216. doi: 10.1243/09544100JAER01 19

Roskam J (1997) Airplane aerodynamics and performance. Lawrence: DAR Corporation.

Skoplaki E, Palyos JA (2009) On the temperature dependence of photovoltaic module electrical performance: a review of efficiency/power correlations. Sol Energ 83(5):614-624.

Song L, Evans JW (2000) Electrochemical-thermal model of lithium polymer batteries. J Electrochem Soc 147(6):2086-2095. doi: $10.1149 / 1.1393490$

Sun K, Zhu M, Wang L, Liu H (2015) Analysis of the hybrid power system for high-altitude unmanned aircraft. Advances in Materials Science and Engineering 2015(2015):Article ID 380708 .

Tornado® (2001) A vortex lattice method implemented in MATLAB; [accessed 2016 May 4]. http://tornado.redhammer.se/

Wilkins G, Fourie D, Meyer J (2009) Critical design parameters for a low altitude long endurance solar powered UAV. Proceedings of the AFRICON 2009; Naibori, Kenia.

Youngblood JW, Talay TA, Pegg RJ (1984) Design of longendurance unmanned airplanes incorporating solar and fuel cell propulsion. Proceedings of the 2Oth Joint Propulsion Conference; Cincinnati, USA. 